Published by Avanti Publishers

Global Journal of Earth

Science and Engineering

ISSN (online): 2409-5710

\title{
Modified Presplit Blast Design and its Implementation to Control Near Field Blast Vibrations
}

\author{
D.L.S. Rasagna ${ }^{1, *}$, K.S.N. Reddy ${ }^{2}$, Sanjay Singh ${ }^{3}$ and Sudip Das ${ }^{3}$ \\ ${ }^{1}$ ITD Cementation India Ltd., Bangalore, India. \\ ${ }^{2}$ Geology Department, Andhra University, India. \\ 3/TD Cementation, Bangalore Project Phase -II, India.
}

\section{ARTICLE INFO}

Article Type: Research Article

Keywords:

Metro projects

Drilling and Blasting

Controlled Blasting

Near field Blast Vibrations

Peak Particle velocity

Timeline:

Received: July 29, 2021

Accepted: November 11, 2021

Published: December 16, 2021

Citation: Rasagna DLS, Reddy KSN, Singh S, Das S. Modified Presplit Blast Design and its Implementation to Control Near Field Blast Vibrations. Glob J Earth Sci Eng. 2021; 8: 62-71.

DOl: https://doi.org/10.15377/2409-5710.2021.08.5

\begin{abstract}
The development of urban infrastructure projects like metro rail projects in the major cities in India is one of the challenging tasks due to several site construction and operating constraints. These rapid transit systems (RTS) are conceived to minimise traffic congestion by providing commuters with fast and efficient transportation alternatives. One such project is the Phase-II of the ongoing Bangalore Underground Metrorail Project. The design and construction of the metro rail project require sound engineering judgment and field experience on envisaged strata conditions along the proposed route alignment.

The important factors that govern the excavation cycle depend on Rock mass material properties, efficient blast design and construction performance. All these considerations needs to be evaluated for achieving safe, cost-effective excavation design layouts. Proper blast design and safe blasting operations play a key role in achieving good fragmentation, minimising over break and equipment downtime. Site-specific innovative methods on controlled blasting techniques are being experimented with and demonstrated to minimise the ground vibrations. The major challenge lies with the design of efficient and smooth wall blasting techniques to safeguard the old heritage buildings and other subsurface structures and utilities.
\end{abstract}

*Corresponding Author Email: rasagna28@gmail.com Tel: 9494543319

(c)2021 Rasagna et al. Published by Avanti Publishers. This is an open access article licensed under the terms of the Creative Commons Attribution Non-Commercial License which permits unrestricted, non-commercial use, distribution and reproduction in any medium, provided the work is properly cited. (http://creativecommons.org/licenses/by-nc/4.0/) 


\section{Introduction}

For any type of rock excavation design, conventional drilling and blasting techniques are widely adopted in construction engineering projects. For subsurface construction projects such as tunnelling and underground metro projects, precision blasting methods are preferred over conventional methods to minimize the ground vibrations and least damage to surrounding rock.

Perimeter blasting techniques limit the damage to the final walls of the excavation boundary. The most common method widely employed is pre splitting, which involves the formation of crack coincident with the excavation boundary, prior to firing the main blast. The effect of rock strength parameters, structural defects, groundwater regime plays a major role in determining the excavation size, shape and type of desired support.

Presplit blasting helps in controlling the generation of fly rock, minimising the blast-induced ground vibrations and air overpressure. Minimizing the near field blast vibrations is one of the major concerns in urban and densely populated metro rail construction Projects.

This case study presented showcasing the problems encountered during the construction of the metro rail project with reference to the design of suitable blasting design and applications of modified presplit design on controlling near field blast vibrations.

The Phase-II of Bangalore metro rail project involves the construction of two lines on standard gauge tracks to the extension of both corridors built-in Phase-I, in all four directions. Bangalore Underground metro rail project, Phase II contains 12 No's of underground metro stations and allied works. Out of which 8numbers of metro stations will be excavated mostly in hard rock. Drilling and blasting methods of excavation are being adopted to reduce the noise generated due to mechanised operations. The proposed layout in Venkateshpura metro station will encounter mostly hard rock formations from the south shaft to the North, it will pass close to the Income Tax Building, which is $8-12 \mathrm{~m}$ away from the shaft. The plan of the proposed Layout is shown in Fig. (1).

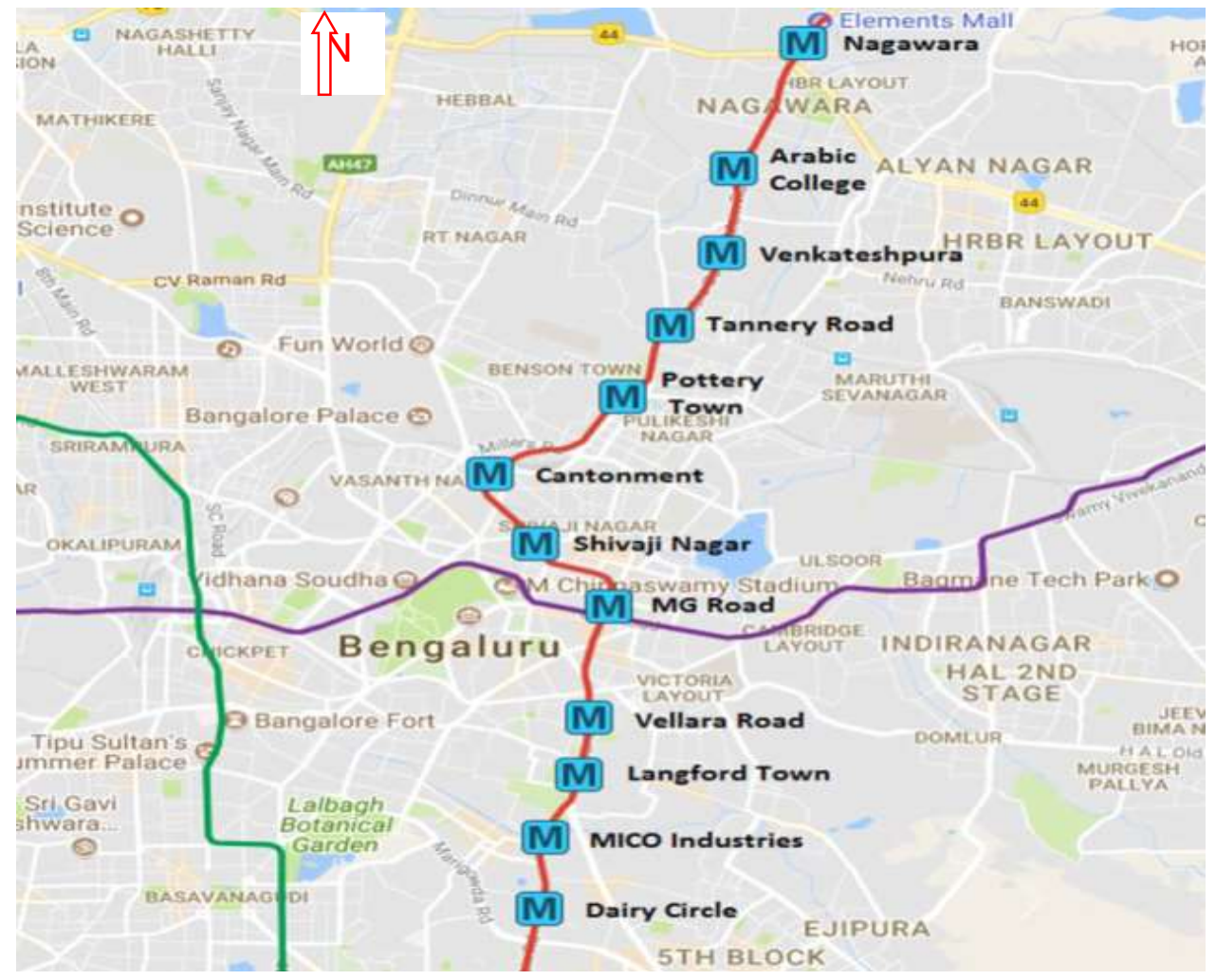

Figure 1: Sketch map showing Proposed Layout plan for Bangalore Underground Metro Rail Project-Phase II (Not to Scale). 


\section{Site Geology}

The general geology of Bangalore and its surrounding areas in which the metro rail project has been planned comprise of Archean Group of rocks dated 2.5 to 3.4 billion years. These rocks mostly belong to the peninsular gneissic complex (Smeeth, W.F. 1916) [2], with small patches of hornblende schist in the northern part and intrusive Closepet granites all along the western part of the district. They are essentially of granodioritic and granitic in composition which is formed due to several thermal-tectonic movements with a large influx of sialic materials.

For understanding the subsurface geology connected to the proposed layout, 11 numbers of cored boreholes were drilled along the aligned route of station locations for conducting field and laboratory investigations.

These boreholes were drilled from the surface up to depth 22.0 to $25.0 \mathrm{~m}$ in different types of soil/rock formations. Drilling operations were performed by deploying mechanically operated soil boring equipment using rotary drilling with a double tube core barrel and diamond bit tool at site as per IS: 1892-1979 standards (Ref.2).

The topsoil layer is predominantly composed of silty sand /residual silt and clay, which acts as a nominal interstitial binder. This overburden material in top layers is generally found as loose to medium compact condition, moist with especially in areas near to groundwater Table 1 . The thickness of the overburden material varied from $2.5 \mathrm{~m}$ to $4 \mathrm{~m}$ due to the effect of differential weathering. The grade of weathered rock varies from loose yellowish silt to medium to high weathered granitic genesis. Underneath the overburden, the rock condition varies from weathered to hard and compact granite gneissic rock.

\section{Case Study}

The Major problems encountered in blasting operations are ground vibrations, fly rock and noise. Ground vibrations cause damage to structures and annoyance to residents in neighbouring areas, in case the intensity is above threshold values. A threshold value of ground vibration varies for different types of structures. In most cases, it also happens that though the intensity of ground vibrations is much lower than safe limits, complaints still keep pouring in due to psychological factors of the people.

Noise generated during blasting operations is a major problem as human beings are very sensitive to noise even though its effect is for a very short duration. Fly rock is another major problem that may cause damage to structures in the vicinity of excavation works and may also result in serious to fatal accidents if proper care is not taken. In some extreme cases, environmental problems may endanger the operation of the project itself. It is, therefore, important to evaluate the impact of these risks/problems in order to design safe control measures.

Table 1: Ground vibrations standards in different countries.

\begin{tabular}{|c|c|c|}
\hline Country & Type of Structure & Permissible PPV \\
\hline \hline UK (Ashley\& Parkes, 1976) [2] & Ancient \&historic monuments & $7.5 \mathrm{~mm} / \mathrm{s}$ \\
\hline Erstwhile USSR (Fadeevetal.,1987) [3] & $\begin{array}{c}\text { Hospitals (moresensitive) - } \\
\text { no mention of historical or archeological monuments }\end{array}$ & $8.0 \mathrm{~mm} / \mathrm{s}$ \\
Norms in India by -DGMS (Anon, 1997) [1] & Objects of historical importance \&sensitives tructures & $2 \mathrm{~mm} / \mathrm{s} \mathrm{for<8Hz}$ \\
& & $5 \mathrm{~mm} / \mathrm{sfor} 8-25 \mathrm{~Hz}$ \\
$10 \mathrm{~mm} / \mathrm{s} \mathrm{for}>25 \mathrm{~Hz}$ & \\
\hline
\end{tabular}

\subsection{Design of Modified Presplit Blast}

Prior to the commencement of Modified Presplit Blast design, the core samples that were obtained through double tube core barrel were studied for rock quality assessment, structural discontinuities, strength properties and related geotechnical parameters. The strata conditions are varying in rock grade from South Shaft towards north Shaft. 
There is an alteration in the strata condition throughout the Venkateshpura metro station, which varied from loose to very dense yellowish-brown silt to Fresh Intact, Foliated Greyish White, and Coarse-Grained Quartz rich formation. The water table depth is varying between $2.5 \mathrm{~m}$ to $4 \mathrm{~m}$ in between the bore hole numbers 20 to 30 . RQD of rock varied from $60 \%$ to $100 \%$ below $6 \mathrm{~m}$ depth up to $30 \mathrm{~m}$. In total, 11 numbers of boreholes were drilled in the proposed alignment which covers the Venkateshpura Metro station.

Before conducting trial blasts, line drilling was carried out near the proposed Venkateshpura Underground Metro station site as a periphery or last line of excavation to minimize the effect of blast and to maintain a smooth wall. Towards the west side of the blasting area, lies the income tax building layout which is $8 \mathrm{~m}$ away from the last line of excavation. On the other side of the metro station, there is a way connected towards the highway. A preblast survey was taken up by scientists before commencing the modified presplit design for blasting operations. All the buildings and structures in the vicinity of the excavation site were identified and marked. Different structures were assigned threshold ground vibration value levels of $2 \mathrm{~mm} / \mathrm{s}, 5 \mathrm{~mm} / \mathrm{s}$, and $10 \mathrm{~mm} / \mathrm{s}$ respectively, as per the prescribed limit by the Director-General of Mines Safety (1997) [3].

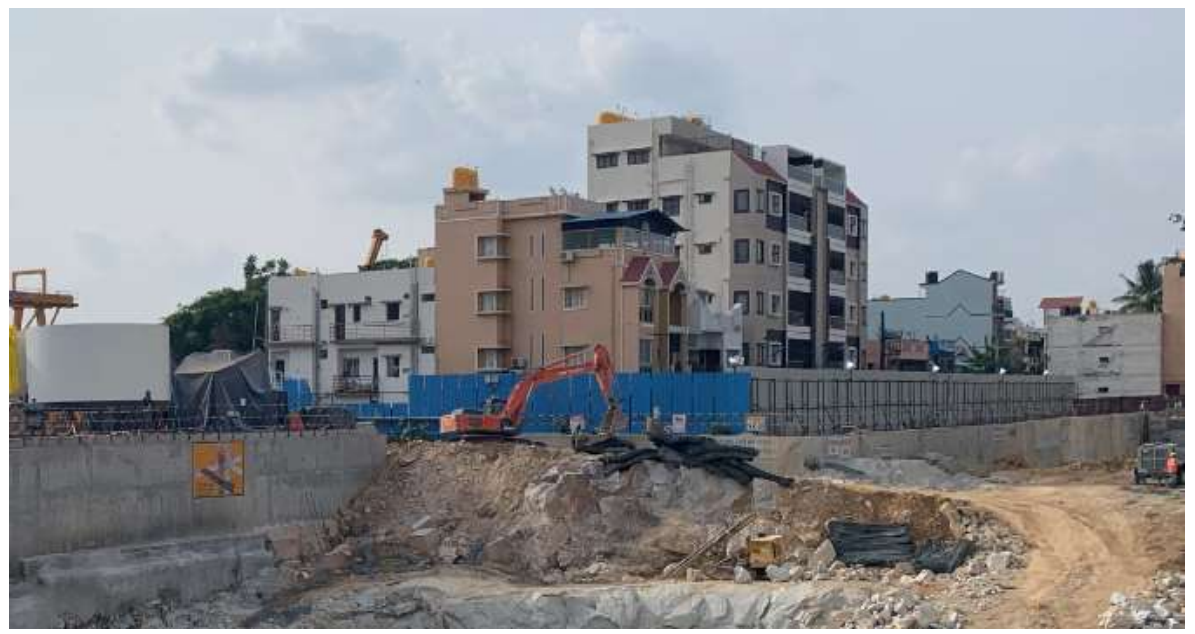

Figure 2: Some important structures around rock excavation.

The Following are some of the side effects of near field blast vibrations (Fig. 3). These include the level of ground vibrations beyond the threshold values, which need to be controlled effectively to minimise the damage to structures as well as to avoid public litigation problems. Fly rock generation is also a very important factor, which needs to be addressed before designing a proper blast, especially in densely crowded areas. The other factor is damage caused by blasting to retaining wall or D-wall. These are the side effects of near field blasting.

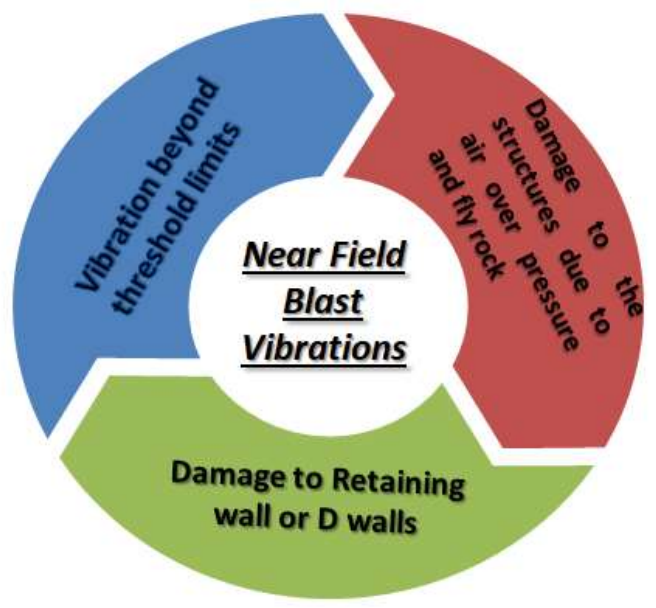

Figure 3: Side effects of near field Blast Vibrations. 


\section{Design Methodology}

The primary aim is to develop a Modified Presplit blast-induced crack along the rock strata to reduce the passage of ground vibrations towards the Income-tax building. The crack serves as a vent for the release of explosive gases by the production blast holes. Based on the above theory, a modified Presplit blast design technique was developed which was successfully implemented in many metro projects to reduce near field blast vibrations. This technique is designed by combining large diameter holes $(115 \mathrm{~mm})$ and alternative small diameter $(32 \mathrm{~mm})$ holes by using a Ground anchoring rig machine and jack hammer. In this method, it has been suggested to drill a second line of row holes along with line drilling in order to minimize the vibration generated by presplit blast.

This technique can be followed where line drilling itself cannot control blast vibrations and where conventional presplit blast fails to maintain threshold limits. This method is easy to operate effectively in safety compliance of blasting in close proximity and is also cost-effective.

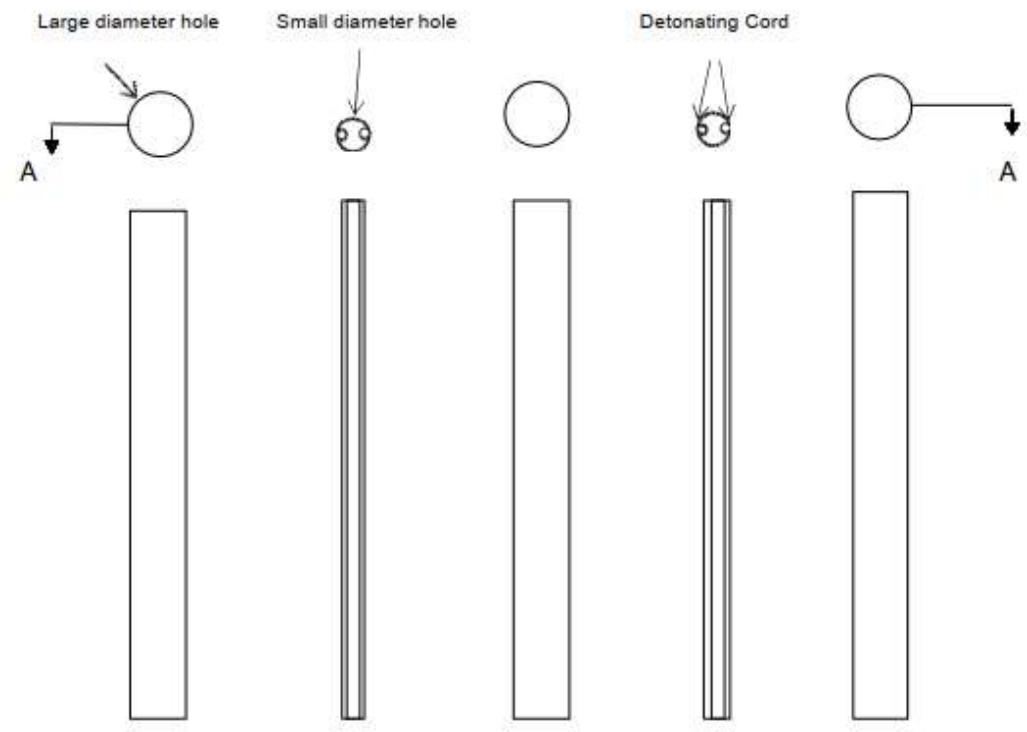

(Section $A-A)$ - Not to scale

Figure 4: Modified Presplit design of large and small diameter holes.

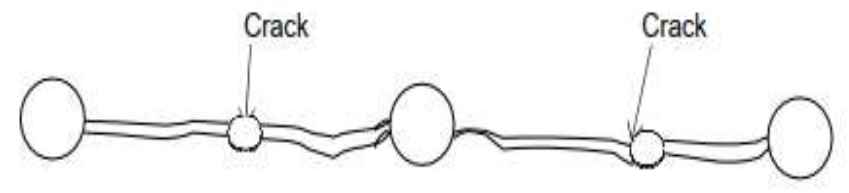

Post Blast

Figure 5: Imaginary post blast generated crack.

Fig. (5) represents the post-blast generated rock in which crack propagation is clearly shown as a continuous one between the two large holes.

After performing the site preparation work by drilling, with ground anchor rig and jackhammer, loading and stemming of small diameter holes to be conducted by using Detonating fuse as a primer. Total6no's of the trial blast was conducted with $6-12$ holes in each blast. Presplit Blast Induced vibrations were within Threshold limits. Based on the frequency, the accepted threshold limit is $15 \mathrm{~mm} / \mathrm{s}$ near the building. All our Vibration values are within the limits. 


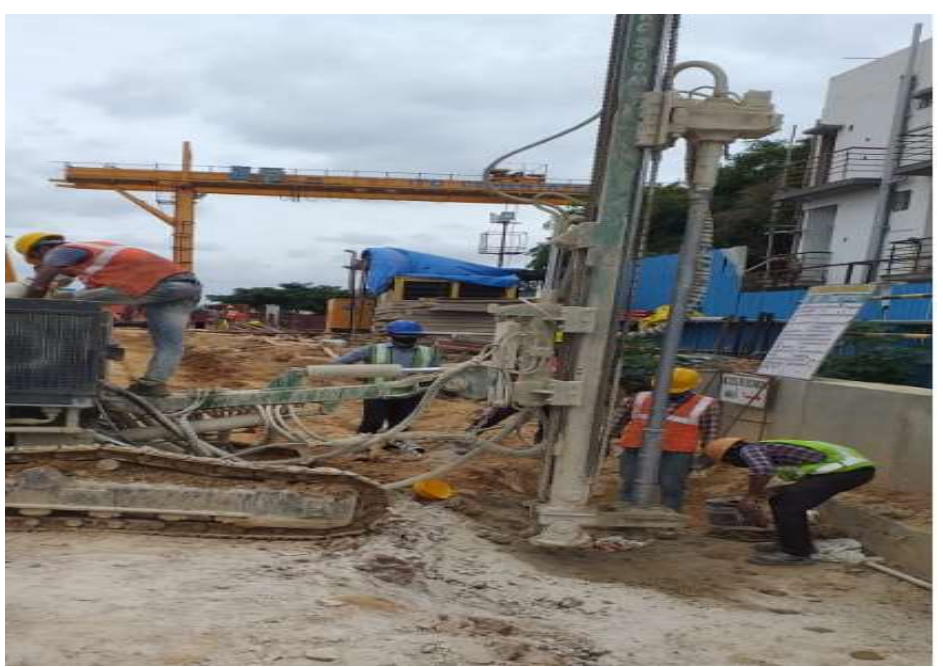

Figure 6: (Step .1). Drilling work for Presplit line.

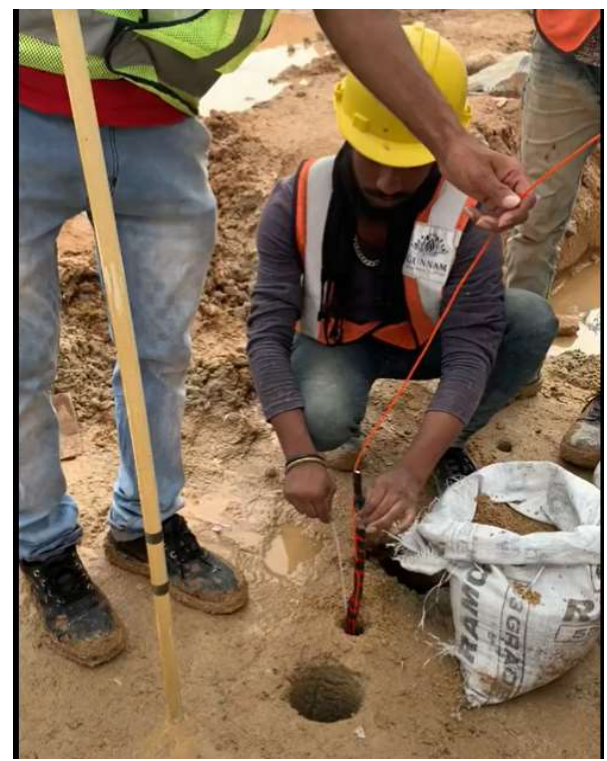

Figure 7: Loading of small diameter holes with Detonating Fuses primer.

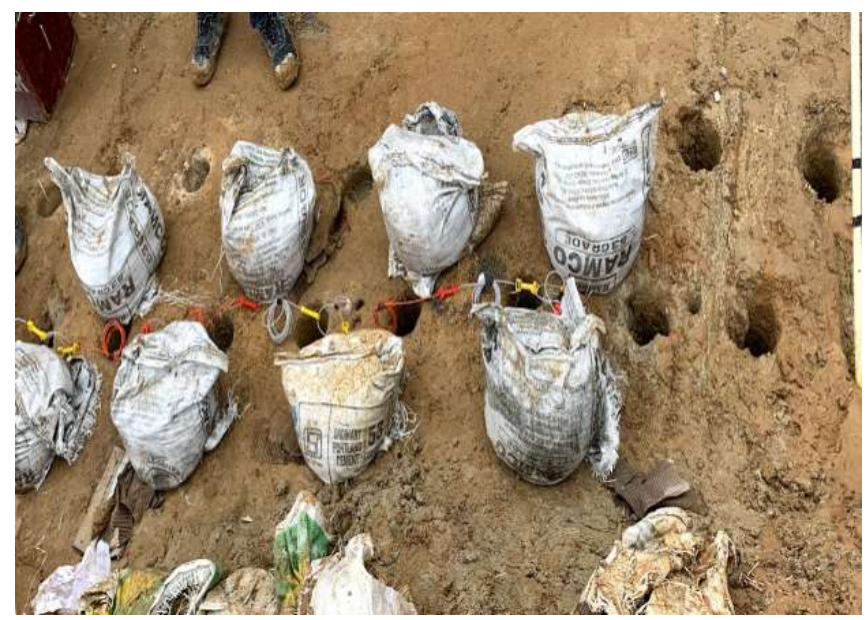

Figure 8: Connections and preliminary muffling with sand bags. 
Three layers of muffling system were practised at the site to control fly rock from the proposed blast. Fine Sandbags were placed over the connected holes on which 1"x1" SWG wire mesh was placed. 3x4m in dimension and $200 \mathrm{~mm}$ thicknesses Rubber mats were used as the final muffling layer. High barricades were placed along all sides which is $5 \mathrm{~m}$ above the station wall to control the side effects of blasting and to isolate the blasting zone from adjacent habitats and traffic.

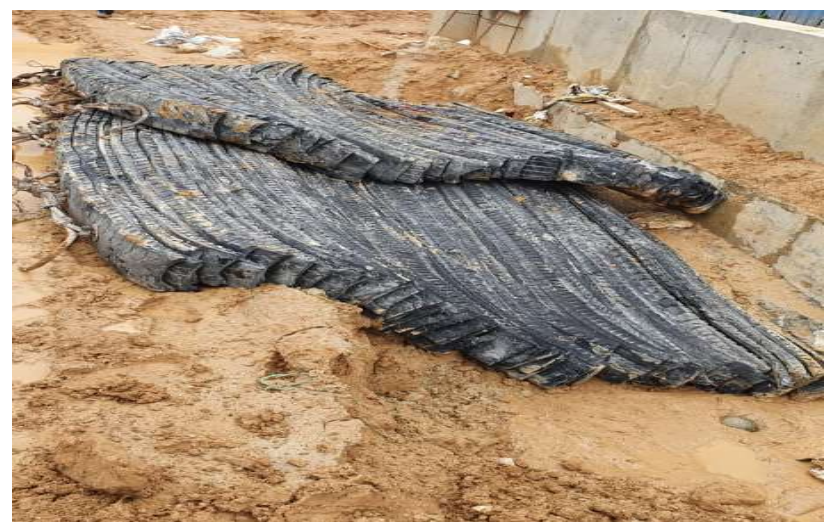

Figure 9: Rubber mats placed over the presplit blast.

Three No's of portable micromates/seismographs from Instatel, Canada were placed at every $5 \mathrm{~m}$ interval of distance and also near to buildings to monitor Presplit Blast Induced Ground Vibrations and air overpressure. A portable microphone is also attached with the seismograph that can pick up and record the attenuation levels of Presplit blast-induced vibrations.

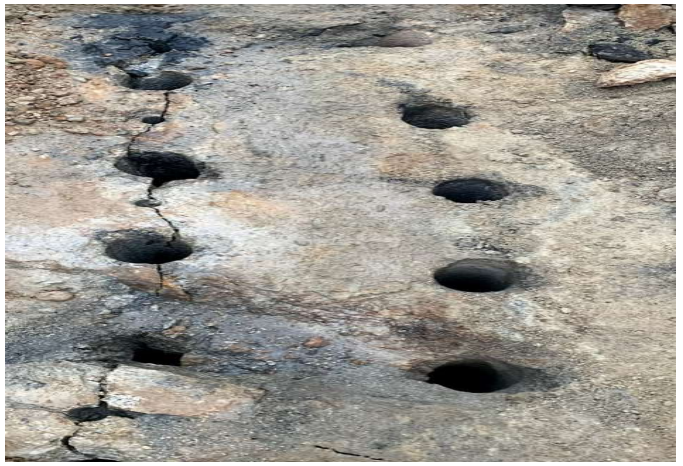

Figure 10: Post blast: Crack generated through Modified presplit Blast.

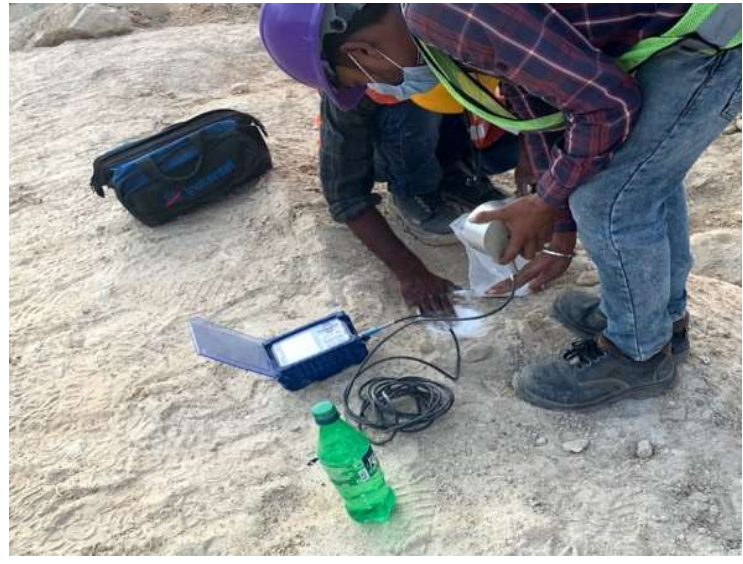

Figure 11: Seismograph location near to presplit blast. 
The peak particle velocity (PPV) levels observed from these blasts are within threshold limits as per Frequency limits and can consider being "safe" for structures. (Ref DGMSCircular 1997 on Blast vibration for mines and structures) [3].

\subsection{Estimation of Peak Particle Velocity}

Based on the above data set, Table 2, shows a plot of scaled distance versus PPV $(\mathrm{mm} / \mathrm{s})$ on a double log graph. The regression analysis was carried out based on the above data set. In the below graph, $Y$ represents Vmax and $x$ represents Scaled distance.

Table 2: Modified Presplit Blast details.

\begin{tabular}{|c|c|c|c|c|}
\hline Blast No. & No Of Holes & MCD (Grams) & $\begin{array}{c}\text { Distance From Blast } \\
\text { to Sensor(M) }\end{array}$ \\
\hline \hline 1 & 6 & 96 & 12 & 16 \\
\hline 2 & 11 & 104 & 14 & 5.147 \\
\hline 3 & 11 & 104 & 26 & 5.76 \\
\hline 4 & 10 & 108 & 24 & 5.210 \\
\hline 5 & 9 & 104 & 101 & 22 \\
\hline
\end{tabular}

\footnotetext{
$\operatorname{Vmax}=k(S D)^{-n}$

$\mathrm{V}=$ Peak particle velocity,

$\mathrm{SD}=$ Scaled distance $\left(\mathrm{D} / \mathrm{Q}^{\wedge} 0.5\right)$

$\mathrm{D}=$ Distance from blast to monitoring station $(\mathrm{m})$

$\mathrm{Q}=$ maximum charge per delay $(\mathrm{kg})$
}

The higher the correlation value R2 value i.e., 0.855 indicated that the data is reliable. Based on the abovederived values maximum safe charge per delay has been calculated from the attenuation characteristics, for the existing ground conditions and further blasting practice.

Usage of Detonating fuse as a substitute of emulsion type explosive resulted in fine cracks. Modified Presplit design is more in usage then general conventional presplit blast in controlling vibrations and providing a vent for escape of energy. Below are the advantages of this design.

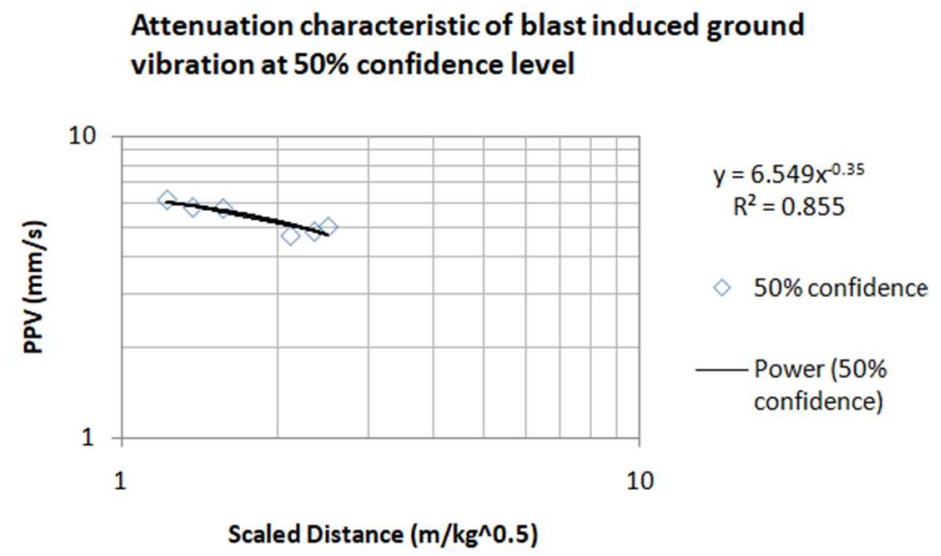

Figure 12: Plot showing Attenuation characteristics of Modified Presplit Blast Induced Vibrations. 


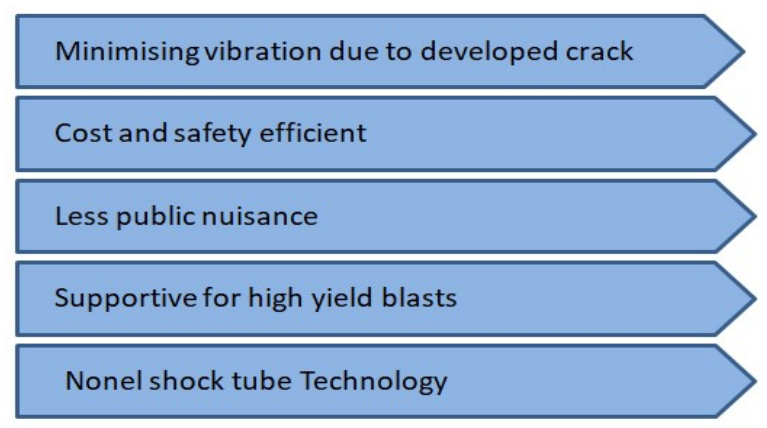

Figure 13: Advantages of Modified Presplit Design.

\section{CONCLUSIONS}

The main objective of pre-splitting blasting is to produce an artificial surface of separation between the blasted rock mass and the remaining rock mass on the final wall, which will lead to a smooth remaining wall without any/minimum back-break. In this study, a modified presplit blast has been performed which resulted in low values of ground vibration and air overpressure. A number of factors influence the intensity of ground vibrations and the predominant one is Maximum Charge per Delay (MCD). It is established by various research studies that as MCD increase, the intensity of ground vibrations also increases and vice versa. To reduce vibration levels, the MCD should be decreased by introducing a delay between holes or group of holes and/or by deck charging etc. If a large number of holes is involved in bigger projects, a delay element in the blast round can be achieved using detonating cord coupled with cord relays. However, detonating cord produces higher noise levels due to the high gram mage of PETN in the cord and also fly rock. Nonelectric based shock tube detonators with surface connectors provide a good alternative to conventional systems. A major advantage of this system is that it ensures true bottom initiation and it gives lesser noise levels compared to detonating cord initiated blasts.

Another important factor is the mechanism by which the pre-split line functions to protect the final wall of the excavation. In fact, the published research indicated that the pre-spilt line is actually formed by the borehole pressures generated within the pre-split holes causing the rock to fall in tension along that line.

The blast design and its implementation at the site is the combination of proper blast design, selection of proper explosive as per site conditions. A number of factors influence the intensity of ground vibrations, including Maximum Charge per Delay (MCD).To reduce vibration levels, the MCD should be decreased by using the double delay between holes or group of holes by deck charging. For a large number of holes, the delay element in the blast round can be achieved using detonating cord coupled with cord delays. Non-electric shock tube detonators (NONEL) with surface connectors provide a safe alternative to overcome this problem. A major advantage of this system is that it ensures true bottom initiation and it gives lesser noise levels compared to detonating cord initiated blasts. The other effective method to control fly rock is the muffling arrangement.

\section{ACKNOWLEDGEMENTS}

The authors wish to express their gratitude to the management of ITD Cementation for providing an opportunity to take up the scientific investigations at the Bangalore metro rail project. During the course of these investigations, the management of ITD Cementation provided the necessary data and site facilities connected to the study.

\section{REFERENCES}

[1] IS: 1892-1979(Reaffirmed 2002) Indian Standard Code of Practice for subsurface Investigation for Foundation.

[2] Smeeth WF. (1921): Peninsular Gneiss Complex, Memoirs of Geological Survey of India. 1935; 68: 109.

[3] DGMS (Tech)/S\&T, No.7, Dated 29-08-1997.

[4] Ashley C, Parkes DB. Blasting in urban areas, Jl. Tunnels \&Tunnelling, 1976; 8(6): 60-67. 
[5] Fadeev AB, Glosman LM, Kurtuzov MI, Safonov LV. Seismic control of mine and quarry blasting in the USSR. Proc. 6th ISRM Conf. Rock Mechanics, Canada, 1987; 1: 617-619.

[6] Nicholls HR, Johnson CF, Duvall WL. Blasting vibrations and their effects on structures, HSRM Bull. 1971; 656.

[7] Sastry VR, Ram Chandar K. Risk Management in the near vicinity of blasting. The Indian Mining \& Engineering Journal 2004; March: 1928.

[8] Calder PN, Tuomi JN. Control blasting at shermanmine,Proc. 6th Annual Conf. on 'Explosives and blasting technique', 1980; 312-330, Montville, $\mathrm{OH}$, Society of Explosives Engineers.

[9] Chiappetta RF. The importance of pre-splitting and fieldcontrols to maintain stable high walls, eliminate coal damage andover break, Proc. 10th High-tech Seminar on 'State of the art,blasting technology, instrumentation and explosives application',GI-48. 2001; 22-26, Nashville, TN.

[10] Enayatollahi I, Aghajani-Bazzazi A. Evaluation of salt-ANFOmixtures in back break reduction by data envelopment analysis, rockfragmentation by blasting, Proc. 9th Int. Symp. on 'Rock fragmentation by blasting', FRAGBLAST 2010; 9: 127-133, Granada, Spain.

[11] Karimi Nasab S, Hojat A, Kamkar-Rouhani A, Akbari Javar H, Maknooni S. Successful use of geoelectrical surveys inarea 3 of the Gol-eGohar Iron Ore Mine, Iran, MineWaterEnviron., 2011; 30(3): 208-215.

[12] Singh PK, Roy MP, Paswan RK. Controlled blastingfor long term stability of pit-walls. Int J Rock Mech Min Sci. $2014 ; 70: 388-399$.

[13] Workman JL, Calder PN. Predicting and controllingexcessiveflyrock, Coal, 1994; 99(9): 26.

[14] Worsey PN. Effect of discontinuity orientation on the successof pre-split blasting, Proc. Tenth Annual Conf. on 'Explosivesand blasting technique', 1984; 197-217, Orlando, FL, Society ofExplosives Engineers. 